\title{
К вопросу об определении понятий «политический язык» и «политический дискурс» в средствах массовой информации
}

\section{Др. АЛИ А. ХАДИ \\ БАГДАДСКИЙ УНИВЕРСИТЕТ ФАКУЛЬТЕТ ЯЗЫКОВ. КАФЕДРА РУССКОГО ЯЗЫКА}

В статье предоставлены определения понятий «политический язык» и «политический дискурс» в средствах массовой информации; представлена структура «общественнополитической лексики», которая состоит из собственно политической лексики и потенциальной политической лексике; обоснованы сущностью феноменов политический язык и политический дискурс; доведено, что понятия «дискурс» интерпретируется с трех основных подходов; определено, что политический язык можно разделить на вербальный и символический; сделана попытка проследить проявление политического языка в языке средств массовой информации; названы основные функции политического языка, которыми являются интерпретационно-оценочная функция, функция формирования политического сознания, функция убеждения и контроля, функцию манипулирования.

Ключевые слова: «политический язык», «политический дискурс», средства массовой информации, «общественно-политическая лексика», «дискурс», вербальный и символический политический язык.

За последние несколько десятилетий многие ученые акцентировали свое внимание на анализе различных аспектов касательно функционирования языка в политике, поэтому термин «политическая речь» стал уже привычным для современного языкознания. При этом при всем исследователи до сих пор не выработали единого подхода к пониманию этого феномена. Даже термин «политическая речь» не является на сегодня общепринятым. Поэтому существует необходимость определить сущность политической речи [3, с. 156], ее особенности, выяснить основное содержание этого понятия и уточнить терминологию, которая с ним связана.

В научной литературе, в связи с рассмотрением политической речи, иногда употребляются такие термины, как «специальный язык политики» или «функциональный стиль политики». Например, по мнению немецкого исследователя В. Шмидта, оба эти термины имеют довольно существенные недостатки: хотя для 
языка политики характерным является наличие специального словаря, но все же он отличается от других специальных языков целым рядом особенностей, главная из которых заключается в том, что специальный словарь политики используется не только в контексте политических текстах, но и в различных сферах повседневной жизни. Кроме того, политические тексты могут принадлежать к разным жанрам, что, в свою очередь, обусловливает существование различных стилей в пределах политического языка. В. Шмидт добавляет, что точный и четкий смысл этого феномена отражают такие термины, как «специальный словарь политики» и «речь политики». Если первый термин включает всю терминологию международных отношений и сферу экономики, реалии внутриполитической и экономической жизни, определения, которые связаны с политическим устройством и общественно-политической жизнью отдельных государств, то термин «речь политики» объединяет специальный словарь политики и особый, прагматический аспект его применения [12, с. 45].

В. Шмидт считает, что к политической речи необходимо отнести всю экономическую терминологию. Конечно, в корпусе политической лексики прослеживается достаточно много терминов из сферы экономики. Это хорошо подтверждается на примере отечественной политической речи, которая за последние годы существенно обогатилась экономическими категориями (например, инфляциия, бюджет и т.д.) [12, с. 45].

Необходимо отметить, что особенности «специального словаря политики» достаточно подробно описаны немецкими лингвистами, которые отмечают, что этот словарь по своей внутренней структуре является очень неоднородным. Обращаем внимание на то, что в политическом языке используется не только специальная политическая лексика и терминология (так называемые «идеологически связанные слова»), но и другие, в принципе политически окрашенные языковые единицы.

Так, Р. Фрайтанг говорит о такой структуре «общественнополитической лексики»: собственно политическая лексика (к которой ученый относит и термины, и слова лозунгов, и жаргонизмы) и потенциальная политическая лексика охватывает лексику общего словарного запаса, языковые явления, которые имеют характер слов лозунгов, названия организаций, партий, государств и т.д. [цит. по тр.: 12, с. 45]. При этом В. Дикман подчеркивает то, что особенностью словаря языка политики является его тесная связь со словарем общенародного языка, так как политическая терминология проникает в общенародный язык с помощью средств массовой информации. Кроме этого, В. 
Дикман выделяет главную особенность языка политики - это ее тесная связь с господствующей идеологией, то есть семантическая детерминированность слов политического языка охарактеризована их принадлежностью к терминологической системе определенной идеологии и ее место в ней [цит. по тр.: 7, c. 78].

Российский исследователь Э. Баталов заметил, что нельзя говорить об обычном формировании особом, «специализированном» языке политики [3, с. 175]. Потому что, как отмечает В. Петров, «политические термины в основном являются полифункциональными» и добавляет, что «они, радикально не меняя свой семантический статус, могут входить и в состав политических теорий, которые имеют более или менее упорядоченную логическую структуру, и в состав газетнополитических и других идеологических текстов, и в состав повседневной речи». Таким образом, политическая терминология не отличается резко в семантическом смысле от повседневной речи, как это, например, характерно для большей части естественно-научной терминологии [15, с. 150]. Придерживаясь мнения Э. Баталова, в политическом языке нужно понимать не конкретный специализированный язык, а каким-то образом сфокусированный язык или его часть - его терминологическую (лексическую) часть, которая употребляется в устных или письменных политических текстах [3, с. 175].

Итак, политический язык нельзя ставить в один ряд с так называемыми «специальными языках», поскольку он тесно переплетается с общеупотребительным языком. К тому же, термин «специальные языки» используются преимущественно специалистами в конкретной сфере, тогда как политическая речь - представителями широких слоев населения. Это и является одной из ее особенностей.

Многогранность феномена политического языка порождает и неоднозначность его трактовки и понимания. На сегодня принято говорить об узком и широком понимании политического языка. Иногда, употребляя это понятие, имеют в виду какую-то узкую cферу, как, например, «язык выступлений политических деятелей», «административный язык» и другие. Некоторые же авторы, наоборот, употребляют это понятие в очень широком смысле. Так, В. Бергедорф под политическим языком понимает «все речевые высказывания, в которых речь идет о политике, а также высказывания, которые продуцируются властями» [цит. по тр.: 12, с. 56]. При этом Д. Мисюров, рассматривая политический язык как один из видов политической символики, склоняется к его широкому пониманию и рассматривает его как «специальную 
терминологию, особые языковые конструкции, применяемые в политической практике». Кроме того, ученый утверждает, что любой текст, посвященный политической жизни, можно считать политическим языком. Это могут быть обращения к народу, стенограммы заседаний, аналитические статьи, лозунги. К политической речи Д. Мисбров относит и законы, конституции, декларации прав и т.п. [12, с. 43-57].

Некоторые ученые (T.A. van Dijk), изучая проблемы функционирования политического языка, принимают для определения этого феномена термин «политический дискурс».

Вообще понятие «дискурс» - это один из самых многозначных терминов, используемых в гуманитарных науках, прямо или косвенно изучающих функционирования языка. Одним из первых, кто предложит слово «дискурс» и обосновал его значение является французский лингвист Э. Бенвинист, который определил его как «речь, которая присвоена тем, кто ею говорит» [цит. по тр.: 12, с. 56]. Основателем уже теории дискурса считается швейцарский ученый Ф. Де Соссюр [17].

Если для французской лингвистической традиции слово «дискурс» - это речь, то вот Р. Барт понимал дискурс как «выражение», «значимое единство, независимо от того, является ли оно словесным или визуальным» [2, с. 500]. Согласно определению Дж. Фиске, стилем считается организация языка за пределами предложения, «расширенное» использование языка, то есть «дискурс» - это речь или система образов, которая сформирована обществом для распространения связанного набора смыслов по определенной теме [цит. по тр.: 17]. При этом при всем поддерживаем позицию российского исследователя М. Ильина, который отмечает, что в целом дискурс можно определить как «последовательное развертывание смыслов, которые выражаются словами и символами, включая значимые действия, то есть аналог речи» [7, с. 78].

На сегодня говорят о трех основных подходах к интерпретации понятия «дискурс»: к первому подходу принадлежит проблемы методологии, а именно лингвистическое использование термина: попытки развития и уточнения уже классических терминов «текст», «язык», «диалог»; второй подход основывается на трудах структуралистов и постструктуралистов (М. Фуко, А. Грейман, Ж. Деррида и другие), где прослеживается стремление уточнить традиционные понятия стиля и индивидуального языка; третий подход связан с именем немецкого социолога и философа и Ю. Хабермаса, который под дискурсом понимает идеальный (особый) вид коммуникации, который, с одной стороны, осуществляется в максимальном отдалении от социальных 
традиций, реальности, авторитета и т.д., а с другой, - имеет целью критическое обоснование и обсуждение действий и взглядов участников любой коммуникации [13].

В «Лингвистическом энциклопедическом словаре» дискурс - это: 1) связный текст в совокупности с экстралингвистическими (прагматическими, социокультурными и другими факторами); 2) текст, взятый в событийном аспекте; 3) речь, которая рассматривается как целенаправленное социальное действие, как составляющая, которая участвует во взаимодействии людей и в механизмах их сознания (когнитивных процессах) [11].

Можем утверждать, что употребление термина «дискурс» в обществоведческих науках является довольно неоднозначным. Такая же ситуация складывается и с термином «политический дискурс». В общем термин «дискурс» попал в широкое научное потребление, в том числе и к политологическому. Однако в лингвистике при непосредственном участии М. Фуко, Р. Барта, Г. Маркузе в конце 1950-х гг. - начале 1960-х гг. в работе «Миф сегодня», которая вышла в 1956 г., Р. Барт еще не употреблял термин «политический дискурс», но уже активно использовал термин «дискурс». Часто в начале 1960-х гг. это понятие появляется и в трудах М. Фуко. В. Долгих предполагает, что термин «политический дискурс» приобретает всемирное научное распространение с выходом труда Г. Маркузе «Одномерный человек: исследование идеологии развитого индустриального общества» (1964 г.) [цит. по тр.: 12]. В этом труде говорится об «универсуме политического дискурса» как о данности, которая является само собой разумеющейся, хотя Г. Маркузе так и не раскрывает его содержания. М. Фуко упоминал о «политическом дискурсе» в своих трудах, выходящих с 1966 г. Исследователь упоминал это понятие с другими видами дискурса - научным, религиозным, экономическим и т.д. В целом же понимание М. Фуко дискурса и его политического характера в значительной степени определило понимание этого понятия и границы его использования в дальнейшем другими исследователями.

Научные труды современных ученых описывают различные определения политического дискурса.

А. Гайдулин отмечает, что политический дискурс - практическое структурирование вербально-смысловой реальности через коммуникативное взаимодействие субъектов властных интенций в политической реальности [цит. по тр.: 6, с. 154]. По его мнению, политический дискурс - это вербализация политических идей для их реализации в политические действия.

Е. Шейгал считает, что под политическим дискурсом следует понимать «любые языковые образования, адресат, субъект или 
содержание которых относится к сфере политики» [16]. По мнению Н. Герасименко, о политическом дискурсе можно говорить как о «сумме языковых образований в конкретном паралингвистическом контексте - контексте политических убеждений и взглядов, политической деятельности, включая негативные ее проявления» [5, с. 22].

При этом А. Белова считает, что политический дискурс существует в устной и письменной форме. К устной форме можно отнести публичные выступления политиков высокого ранга, их интервью, выступления на радио и телевидении, прессконференции, парламентские дебаты, блоки политических новостей в теле- и радиопередачах. К письменной форме политического дискурса относятся различные документы договоры, протоколы, соглашения, рубрики политических новостей в прессе и такие формы политической рекламы, как политические плакаты и открытки [4].

Все упомянутые выше определения можно отнести к широкому пониманию политического дискурса, для которого характерным является включение в это понятие любого актуального использования языка в социально-политической сфере, то есть политический дискурс - это слово о политике, система суждений, наполненных политическим содержанием. Согласно узкому пониманию, политический дискурс - это всего лишь дискурс политиков. Его составляют парламентские дебаты, правительственные обсуждения, партийные программы и выступления политиков. Сторонник предложенной трактовки голландский лингвист Т.А. ван Дейк отмечает, что дискурс является политическим в том случае, когда он сопровождает политический акт в соответствующей политической обстановке; то есть, политический дискурс, по его мнению, формируется в контексте функционирования политических институтов (сессии парламента, заседании правительства, съездов партий) [17].

Достаточно часто исследователи проблем политического языка используют как термин «политический дискурс», так и термин «политическая речь» и, как правило, употребляют их как синонимы. По крайней мере, они не указывают, что как-то различают эти понятия. Только кое-кто пытается развести их. В частности, это делает А. Баранов, по мнению которого политический дискурс - это совокупность всех возможных речевых актов, которые используются в политических обсуждениях и дискуссиях, а также правил публичной политики, которые оформились согласно традиции и были проверены опытом. В политическом языке ученый понимает особую знаковую систему, предназначенную именно для политической 
коммуникации [1]. Поэтому предполагаем, что понятие «политическая речь» является шире понятия «политический дискурс».

В целом же многие российский исследователи чаще всего употребляют термин «политический дискурс», чем западные ученые. Последние пользуются преимущественно терминами «политический язык» или «язык политики».

Приверженность российских ученых к термину «политический дискурс» объясняется тем, что этим термином ученые начали пользоваться в посткоммунистический период, когда популярность приобрели исследования советского и постсоветского языка. Большинство исследователей склоняется к мнению, что на смену советскому политическому языку, для которого характернвым был принудительный монологизм, пришла новая речь, главным признаком которой стал плюралистический диалогизм, или, как отмечает А. Клепиков, «эпоха» молчаливого большинства «уступила место массовому привлечению к политическому дискурсу» - в дискуссии, обсуждения насущных вопросов социально-политической жизни. Поэтому в языке современной политики закрепилось название «политический дискурс», который стал пониматься как «воплощение в языке политической воли и демократического публичного обсуждения и обоснование любых значимых для граждан (политических существ) тем и проблем» [8, с. 25-31]. Но политический язык нельзя сводить только к языку публичных политических дискуссий; сюда входит и язык документов, законов и т.д., что не принадлежит к языку дискуссий уже по своей сути. Поэтому, по нашему мнению, для определения этого феномена целесообразно употреблять именно термин «политическая речь».

Проанализировав и обобщив различные подходы к пониманию проблемы, политический язык можно определить как совокупность вербальных структур, используемых в сфере политики, которые производят воздействие на политическое сознание индивидов и их участие в ходе политических процессов. Предоставить ответ на вопрос об сущзности политического языка невозможно без определения его видов. Немецкий исследователь В. Бергедорф включает в состав политического языка такие подсистемы: речь законодательства и административноправовой терминологии, административный язык или язык управления, речь переговоров, речь политического воспитания, речь политической пропаганды [цит. по тр.: 17]. Американский исследователь М. Эделман, установив взаимосвязь между стилистическими структурами политической речи и еe 
политическими целями, выделил четыре основные разновидности политического языка на основе политической стилистики: язык уговоров, язык закона, административный язык и язык соглашений [цит. по тр.: 17].

В зависимости от формы функционирования и передачи информации, политический язык можно разделить на вербальныій - язык слов и символический - язык определённых специальных знаков, условных эмблем, сигналов, ритуальных действий и т.п. Политический язык можно распределить также на профессиональный специиальный язык политических ведомств (инструкций, переговоров, распоряжений, переписки и т.д.) и общепонятный и более доступный язык публичных политических выступлений (политической информации, докладов, сообщений, митингов, парламентских дебатов и т.д.) цит. по тр.: 17.

Предполагаем, что к политической речи можно отнести, прежде всего, язык публичных выступлений политических деятелей в различных ее проявлениях: заявления, интервью, радио- и телеобращения, пресс-конференции, радио- и теледебаты, выступления перед любой аудиторией с определенной целью. Важным видом политического языка является язык функиионирования политических институтов (речь правительственных заседаний, партийных съездов и т.п.). Особенно здесь привлекает внимание парламентская речь, главная составляющая которой - язык дебатов. К политическому языку относится и язык политической пропаганды $u$ политической рекламы как в устной, так и в письменной форме (в первую очередь - речь листовок, плакатов, радио- и видеороликов). Специфическим видом политического языка является язык политических документов (законы, договоры, соглашения, меморандумы, декларации, программы и уставы политических партий, протоколы заседаний).

Многие проявления политического языка встречаются в языке средств массовой информации. К ним относятся, в частности, речь передач на политические темы, блоки политических новостей на радио- и телевидении, рубрики, которые отводятся политическим событиям в прессе, статей на политические темы, заявления политических комментаторов и обозревателей, материалы специализированных изданий по различным аспектам политики и т. п. Отдельным видом можно считать язык выборов, в которой пересекаются и иногда приобретают своеобразное значение упомянутые выше разновидности политического языка. Политический язык имеет и другие весьма специфические характеристики. Большинство исследователей сходится на том, что характерной особенностью политического языка является 
многозначность ее основной терминологии. С этим тесно связана такая характеристика политического языка, как ее полемичность, проще говоря - направленность на формирование негативного отношения к политическим противникам, которые навязывают общественности свои ценности и оценки. Это, в частности, приводит к тому, что одни и те же термины сторонников разных политических взглядов воспринимаются неоднозначно, а часто и совсем противоположно (коммунизм, фашизм, демократия и т. д.) [5].

Принципиальное отличие политического языка от обычного языка состоит в таком изменении соотношения между словом и значением, при которой привычные языковые единицы получают необычную интерпретацию, a хорошо знакомые ситуации включаются в неожиданные смысловые контексты. То есть, по образному выражению, «вещи уже не называются своими именами».

Политический язык по стилю является очень близким к публицистическому и, в отличие от «специализированных языков», характеризуется преимущественно направленностью на массовую аудиторию. Для политического языка, благодаря объективно присущим ей особенностям, характерной является заданность на воздействие: направленность на внушение определенных взглядов, изменение намерений, мыслей, мотиваций действий. Поэтому она «присваивается», как правило, властью и становится средством распространения нужных политических идей и ценностей этой властью [7].

Среди характеристик политического языка можно назвать и его неопределенность. Политическим текстам не свойственна логическая стройность. Предпочтение отдается общим формулировкам, а не конкретным фактам. Часто используются языковые шаблоны и стереотипы. Неудобные высказывания заменяются условными, а то и такими, что ничего не значат. Политическая речь также предпочитает комментирование, а не информацию. Важной особенностью политического языка является направленность ее аргументов преимущественно на проблемы методологии чувства, а не на разум.

Политический язык выполняет в обществе определенные функции. Одни из них перекликаются с общими функциями языка, другие присущие только ей.

Основной функцией политического языка является информационная, поскольку она, в первую очередь, является средством передачи информации политического содержания. С информационной тесно связана коммуникативная функция, которая заключается в том, что с помощью политического языка, 
налаживается общение, взаимодействие между субъектами политики, в частности - между властью и гражданами.

Политический язык выполняет и интерпретационно-оценочную функиию, поскольку языковые знаки всегда несут в себе определенную оценку, которая, накладываясь на передаваемую с их помощью, придает ей определенную интерпретацию.

Важной является и функция формирования политического сознания. С помощью политического языка происходит отражение политической действительности, при ее посредничестве формируются политические ценности, идеалы, нормы, правила политического поведения, представления о политических институтах, об отношениях между властью и гражданами и т.п. [9].

Одной из определяющих функций, которая выделяет политический язык из общего языкового контекста, является функиия убеждения и контроля. Использование выразительных возможностей языка, подбор языковых знаков, наделение терминов и понятий определенными значениями - все это в политическом языке направляется на осуществление влияния как на индивидуальную, так и на массовое политическое сознание и контроль за поведением граждан. Для политического языка такое влияние является определяющим в политической коммуникации. Она может выполнять и функцию манипулирования, поскольку особенности, объективно присущие языку и коммуникации, позволяют осуществлять скрытое управление сознанием и поведением людей в желаемом для субъектов власти направлении.

Итак, политическая язык является сложным и разноаспектных феноменом, который имеет много проявлений и особенностей, что делает невозможным его однозначное понимание. Существует немало подходов к трактовке понятия политического языка и политического дискурса, что, в значительной степени, объясняется междисциплинарным характером ее исследования. 


\title{
On the question of definition"political language" and " political discourse $\gg$ in the media
}

\author{
ALI ABAULMANAM HADI \\ Baghdad University-Faculty of Languages-Department of Russian \\ Email: alihadi1967@mail.ru
}

\begin{abstract}
The article provides the definitions of "political language" and "political discourse" in the mass media; the structure of "sociopolitical lexicon," has been represented which consists of the political lexicon and potential political vocabulary; the essence of phenomena political language and political discourse has been given; it has been proved that the concept of "discourse" is interpreted due to three main approaches; it has been determined that the political language can be divided into verbal and symbolic ones; an attempt has been traced to show the expression of political language in the language of the mass media; the basic functions of political language have been called which are interpretational-evaluation function, the function of the formation of political consciousness, the function of persuasion and control, the manipulation function.

Key words: "political language", "political discourse", mass media, "the socio-political vocabulary", "discourse", the verbal and symbolic political language.
\end{abstract}

\section{Список использованной литературы:}

1. Баранов А.Н. Политический дискурс: прощание с ритуалом? / А.Н. Баранов // Человек. - 1997. - № 6. - С. 108-118.

2. Барт Р. Избранные работы: Семиотика. Поэтика / Р. Барт. - М. : Прогресс, 1989. - 616 c.

3. Баталов Э.Я. Политическая культура современного американского общества / Э.Я. Баталов. - М. : Наука, 1990. - 256 с.

4. Белова А.Д. Лингвистические аспекты аргументации / А.Д. Белова. - К. : Изд-во Киевского университета, 1997. - 311 с.

5. Герасименко Н.А. Информация и фасцинация в политическом дискурсе / Н.А. Герасименко // Политический дискурс в России. - 1998. - С. 22.

6. Горюнов В.К. Приемы использования языка политики в целях идеологического воздействия / В.К. Горюнов // Язык как средство идеологического воздействия : [сб. обзоров]. - М. : ИНИОН, 1983. - С. 153168.

7. Ильин М.В. Умножение идеологий или проблема «переводимости» политического сознания / М.В. Ильин // Полис. - 1997. - № 4. - С. 78.

8. Клепиков А. Зоополитикон учится говорить: политический дискурс в посткомунистической Украине / А. Клепиков // Политическая мысль. - 1994. - № 3. - C. 25-31. 
9. Крючкова Т.Б. Особенности формирования и развития общественнополитической лексики и терминологии / Т.Б. Крючкова. - М. : Наука, 1989. $151 \mathrm{c}$.

10. Крючкова Т.Б. Язык политики в работах ученых ГДР / Т.Б. Крючкова // Язык как средство идеологического воздействия : [сб. обзоров]. - М. : ИНИОН, 1983. - С. 60-73.

11. Лингвистический энциклопедический словарь. - М. : Советская Энциклопедия, 1990. - 685 с.

12. Мисюров Д.А. Политическая символика: структура и функции / Д.А. Мисюров // Вестник Московского университета. Серия 12. Политические науки. - 1999. - № 1. - С. 43-57.

13. Петров В.В. Логическая семантика и язык политики / В.В. Петров // Новый мировой порядок и политическая общность. - М. : Наука, 1983. - С. 166-173.

14. Ушакин С.А. После модернизма: язык власти или власть языка? / С.А. Ушакин / ОНС. - 1996. - № 3. - С. 130-141.

15. Ушакин С.А. Речь как политическое действие / С.А. Ушакин // Полис. 1995. - № 5. - С. 142-163.

16. Шейгал Е.И. Семиотика политического дискурса / Е.И. Шейгал. Волгоград : Перемена, 2000. - 367 с.

17. Dijk T.A. van What is political discourse analysis? / T.A. van Dijk // Blommaert J., Bulkaen C. Politikal linguistics. - Amsterdam, 1998.

18. Schmidt, Wilhelm; Barnes, W. D. (June 1903). "Schmidt's Sakai and Semang Languages". Journal of the Straits Branch of the Royal Asiatic Society (39). Singapore. pp. $38-45$.

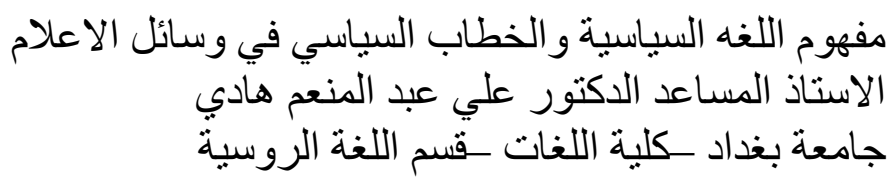

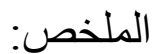

تتناول المقالة على تعريف مفاهيم "اللغة السياسية" و "الخطاب السياسي" في وسائل الإعلام

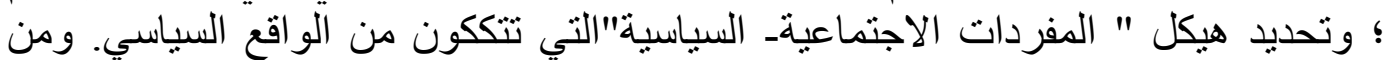

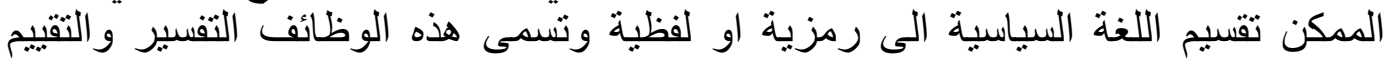
ووظيفة الوعي السياسي ووظيفةالاقناع. الكلمات المفتاحية:" اللغة السياسية"،" الخطاب السياسي"، وسيائل الإعلام" المفردات

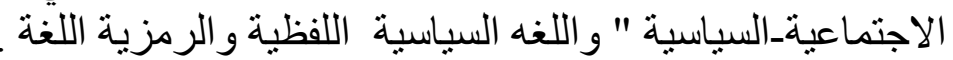

